
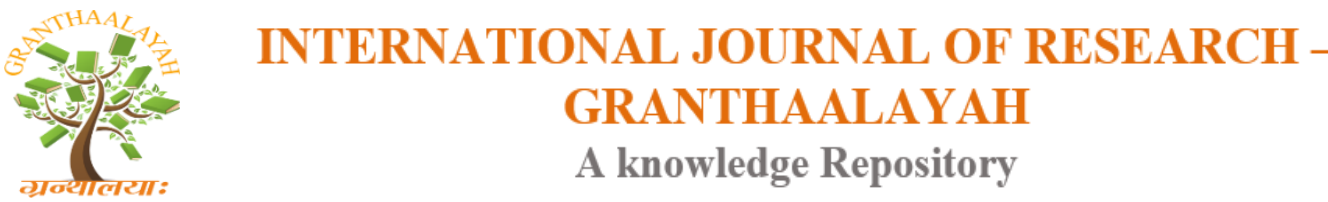

Science

\title{
STUDY AND ANALYSIS OF LIFE OF SILICONE RUBBER COATINGS ON INSULATOR
}

\author{
Dr. S. K. Mahobia*1 \\ ${ }^{* 1}$ Assistant Professor, Department of Physics, Rewa Engineering College, Rewa (M.P.), India
}

DOI: https://doi.org/10.29121/granthaalayah.v5.i2.2017.1723

\begin{abstract}
The coatings have been in service for many years users are beginning to be concerned about the increased risk of flashover which are comes with aging, or the end-of-life, and the course of action that may be necessary for life extension or replacement. Study of the performance characteristics of commercial RTV silicone rubber coatings with various voltages.

Keywords: RTV; Silicone Rubber; Insulator Coatings.

CITE THIS ARTICLE: Dr. S. K. Mahobia (2017). "STUDY AND ANALYSIS OF LIFE OF SILICONE RUBBER COATINGS ON INSULATOR" International Journal of Research - Granthaalayah, 5(2), 191-198. https://doi.org/10.29121/granthaalayah.v5.i2.2017.1723.
\end{abstract}

\section{Introduction}

Silicones are polymers that include silicon together with carbon, hydrogen, oxygen, and sometimes other elements. Some common forms include silicone oil, silicone grease, silicone rubber, silicone resin, and silicone caulk.

\section{Chemical Structure}

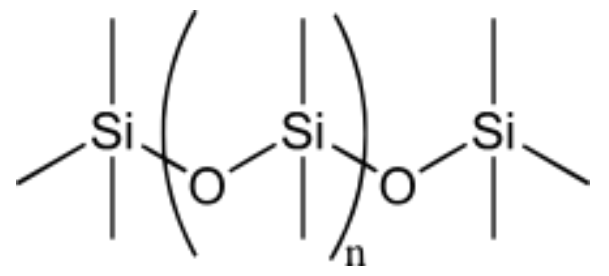

Figure 1: Chemical structure of the silicone polydimethylsiloxane (PDMS) 


\section{Properties}

Silicones exhibit many useful characteristics, including:

- Low thermal conductivity

- Low chemical reactivity

- Low toxicity

- Thermal stability (constancy of properties over a wide temperature range of -100 to 250 $\left.{ }^{\circ} \mathrm{C}\right)$.

- The ability to repel water and form watertight seals.

- Does not stick to many substrates, but adheres very well to others, e.g. glass.

- Does not support microbiological growth.

- Resistance to oxygen, ozone, and ultraviolet (UV) light. This property has led to widespread use of silicones in the construction industry (e.g. coatings, fire protection, glazing seals) and the automotive industry (external gaskets, external trim).

- Electrical insulation properties. Because silicone can be formulated to be electrically insulative or conductive, it is suitable for a wide range of electrical applications.

\section{Types of Insulators}

There are several types of insulators but the most commonly used are pin type, suspension type, strain insulator and shackle insulator.

\subsection{Pin Type Insulators}

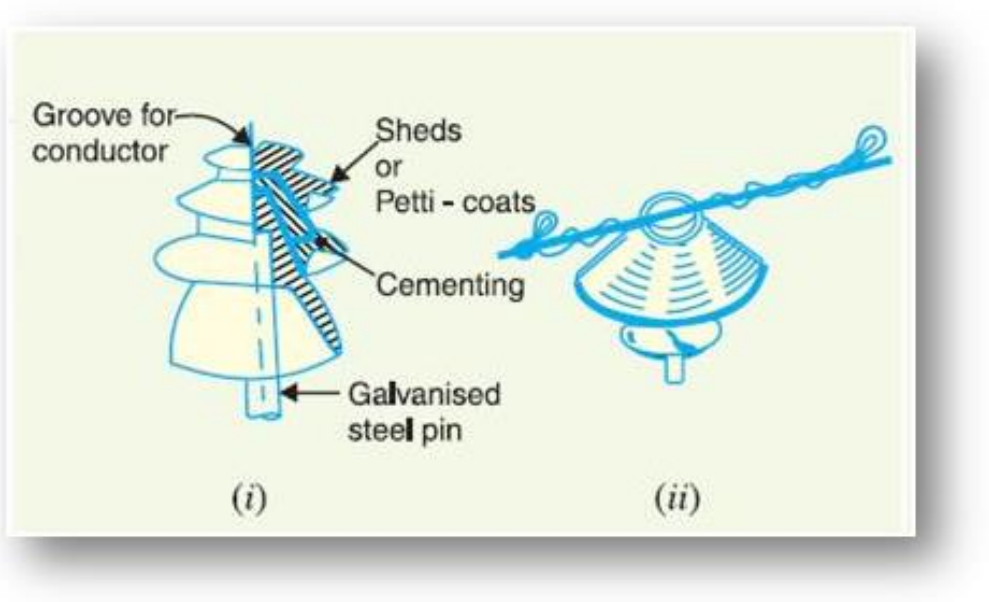

Figure 2: Pin Type Insulator

As the name suggests, the pin type insulator is secured to the cross-arm on the pole. There is a groove on the upper end of the insulator for housing the conductor. The conductor passes through this groove and is bound by the annealed wire of the same material as the conductor. 


\subsection{Causes of Insulator Failures:}

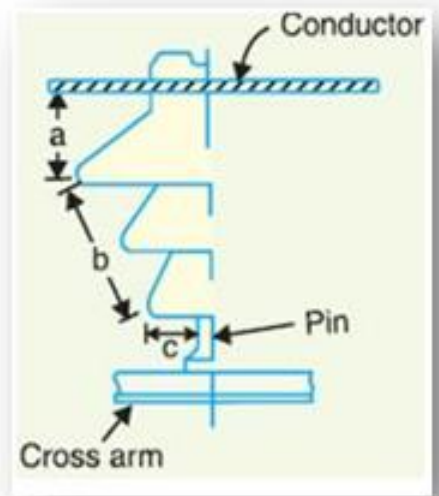

Figure 3: Causes of Failure Diagram

Insulators are required to withstand both mechanical and electrical stresses. The latter type is primarily due to line voltage and may cause the breakdown of the insulator. The electrical breakdown of the insulator can occur either by flash-over or puncture. In flashover, an arc occurs between the line conductor and insulator pin (i.e., earth) and the discharge jumps across the air gaps, following shortest distance.

\subsection{Suspension Type}

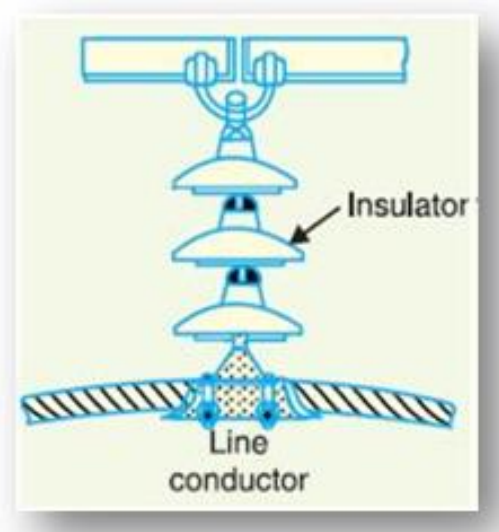

Figure 4: Suspension Type

For high voltages $(>33 \mathrm{kV})$, it is a usual practice to use suspension type insulators shown in Figure. Consist of several porcelain discs connected in series by metal links in the form of a string. The conductor is suspended at the bottom end of this string while the other end of the string is secured to the cross-arm of the tower. Each unit or disc is designed for low voltage, say $11 \mathrm{kV}$. The number of discs in series would obviously depend upon the working voltage. For instance, if the working voltage is $66 \mathrm{kV}$, then six discs in series will be provided on the string. 


\subsection{Strain Insulators}

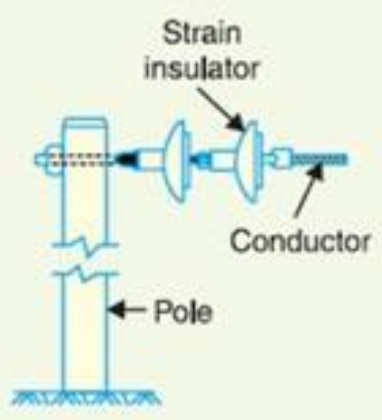

Figure 5: Strain Type Insulator

When there is a dead end of the line or there is corner or sharp curve, the line is subjected to greater tension. In order to relieve the line of excessive tension, strain insulators are used. For low voltage lines $(<11 \mathrm{kV})$, shackle insulators are used as strain insulators.

\subsection{Shackle Insulators}

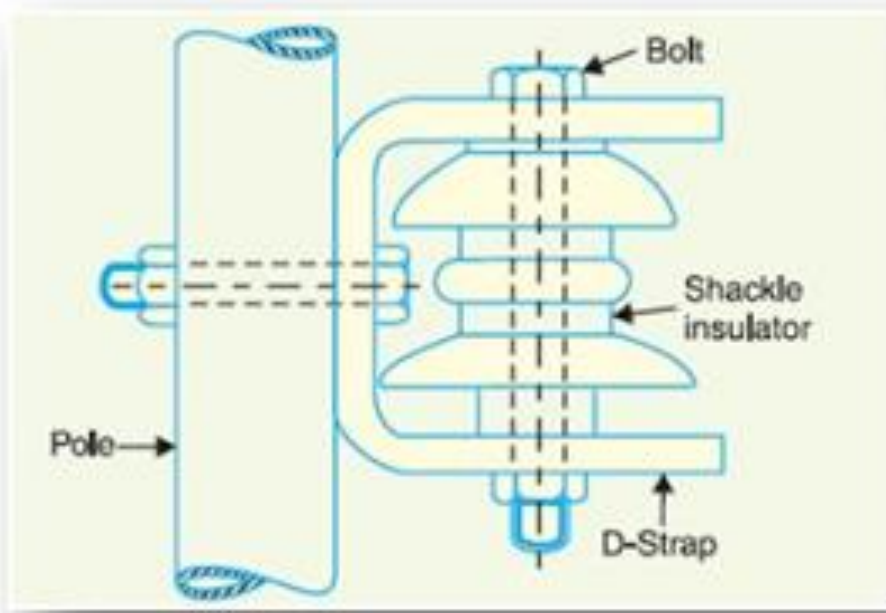

Figure 6: Shackle Type Insulator

In early days, the shackle insulators were used as strain insulators. But now a day, they are frequently used for low voltage distribution lines. Such insulators can be used either in a horizontal position or in a vertical position. They can be directly fixed to the pole with a bolt or to the cross arm. 


\section{Result and Discussion:}

Table 1: Field aged samples of RTV at $30^{\circ} \mathrm{C}$

\begin{tabular}{|c|c|c|c|}
\hline Sr. No. & Time in hours & Contact Angle, Aged & Contact Angle, New \\
\hline 1 & 4 & 70 & 80 \\
\hline 2 & 6 & 75 & 86 \\
\hline 3 & 8 & 80 & 92 \\
\hline 4 & 10 & 85 & 98 \\
\hline
\end{tabular}

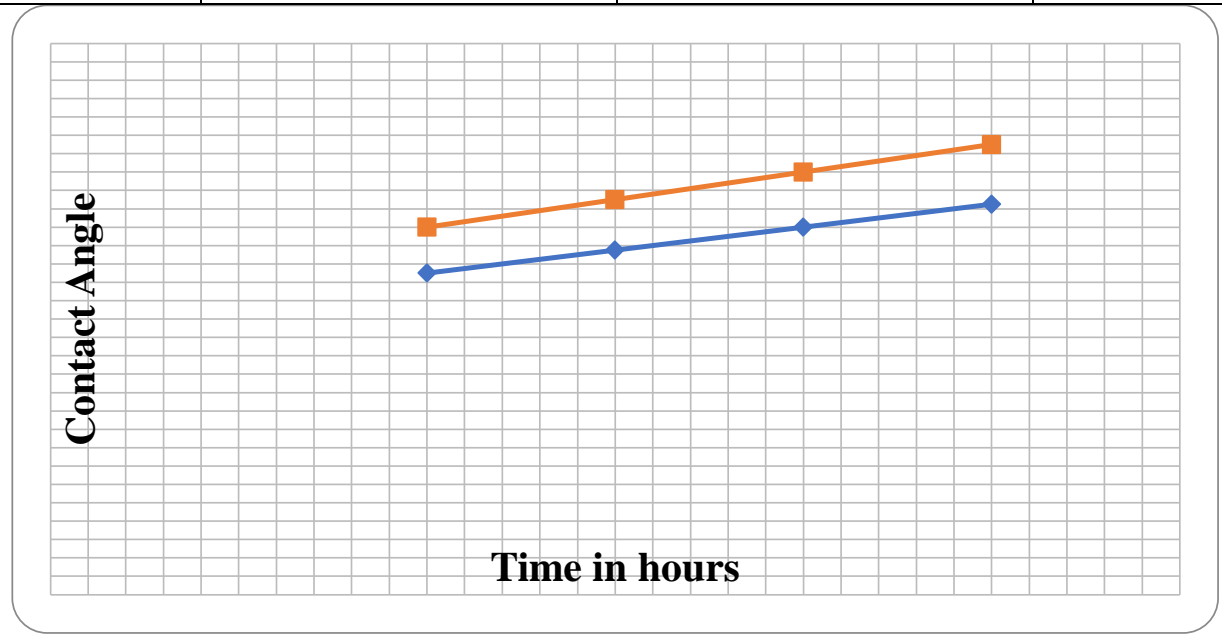

Figure 7: Field aged samples of RTV at $30^{\circ} \mathrm{C}$

Table 2: Field aged samples of RTV at $35^{\circ} \mathrm{C}$

\begin{tabular}{|c|c|c|c|}
\hline Sr. No. & Time in hours & $\begin{array}{c}\text { Contact Angle, } \\
\text { Aged }\end{array}$ & Contact Angle, New \\
\hline 1 & 4 & 72 & 74 \\
\hline 2 & 6 & 88 & 82 \\
\hline 3 & 8 & 92 & 86 \\
\hline 4 & 10 & 96 & 90 \\
\hline
\end{tabular}

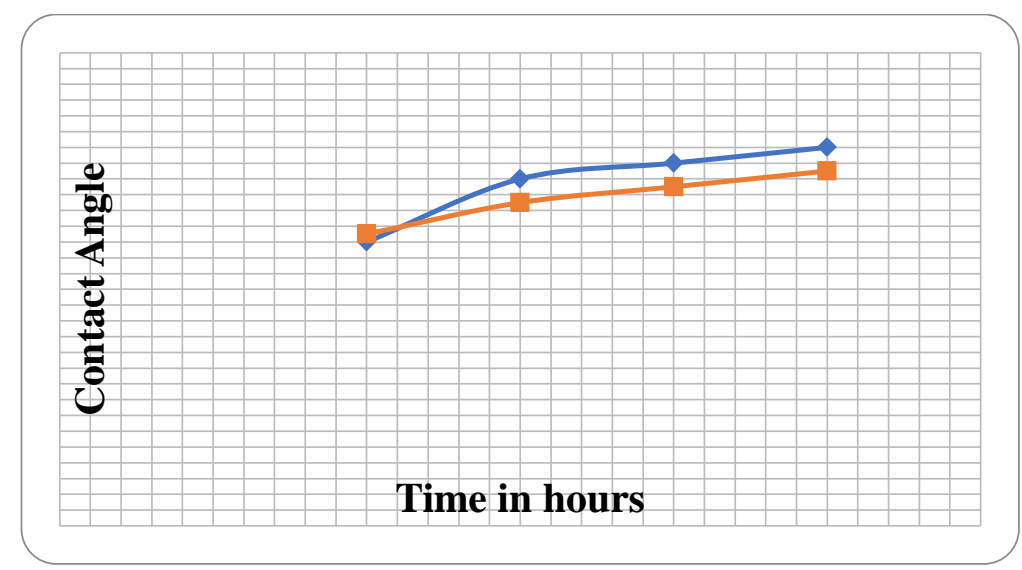

Figure 8: Field aged samples of RTV at $35^{\circ} \mathrm{C}$ 
Table 3: Field aged samples of RTV at $40^{\circ} \mathrm{C}$

\begin{tabular}{|c|c|c|c|}
\hline Sr. No. & Time in hours & Contact Angle, Aged & Contact Angle, New \\
\hline 1 & 4 & 77 & 82 \\
\hline 2 & 6 & 82 & 86 \\
\hline 3 & 8 & 88 & 94 \\
\hline 4 & 10 & 92 & 98 \\
\hline
\end{tabular}

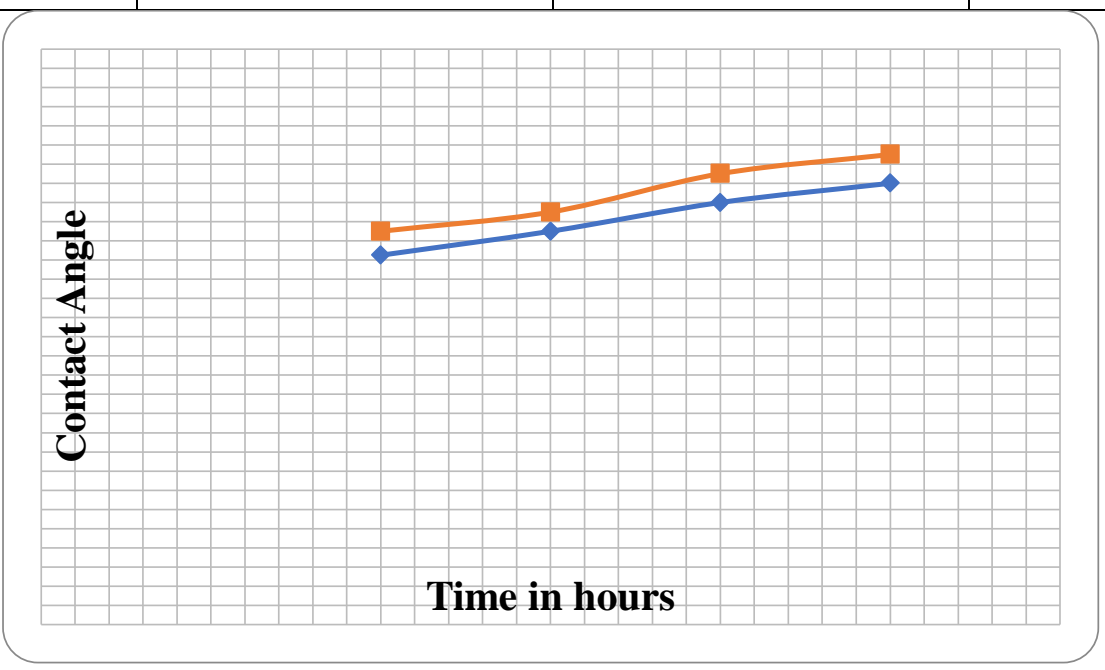

Figure 9: Field aged samples of RTV at $40^{\circ} \mathrm{C}$

Table 4: Field aged samples of RTV at $45^{\circ} \mathrm{C}$

\begin{tabular}{|c|c|c|c|}
\hline Sr. No. & Time in hours & Contact Angle, Aged & Contact Angle, New \\
\hline 1 & 4 & 84 & 90 \\
\hline 2 & 6 & 88 & 96 \\
\hline 3 & 8 & 94 & 102 \\
\hline 4 & 10 & 100 & 110 \\
\hline
\end{tabular}

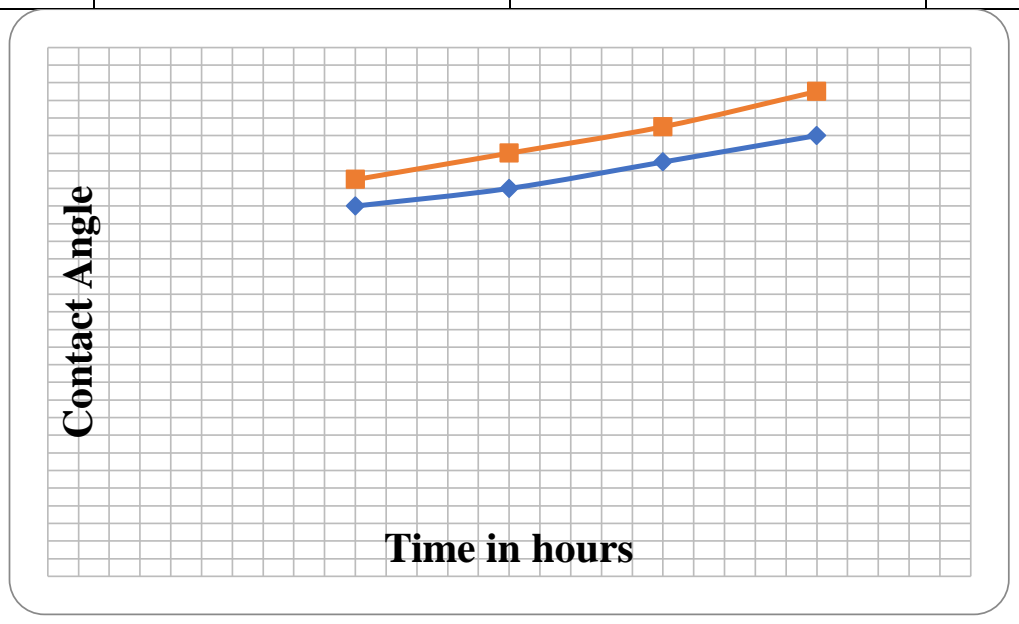

Figure 10: Field aged samples of RTV at $45^{\circ} \mathrm{C}$ 
Table 5: Field aged samples of RTV at $50^{\circ} \mathrm{C}$

\begin{tabular}{|l|l|l|l|}
\hline \multicolumn{1}{|c|}{ Sr. No. } & \multicolumn{1}{|c|}{ Time in hours } & \multicolumn{1}{c|}{$\begin{array}{c}\text { Contact Angle, } \\
\text { Aged }\end{array}$} & Contact Angle, New \\
\hline 1 & 4 & 88 & 91 \\
\hline 2 & 6 & 94 & 98 \\
\hline 3 & 8 & 97 & 105 \\
\hline 4 & 10 & 102 & 115 \\
\hline
\end{tabular}

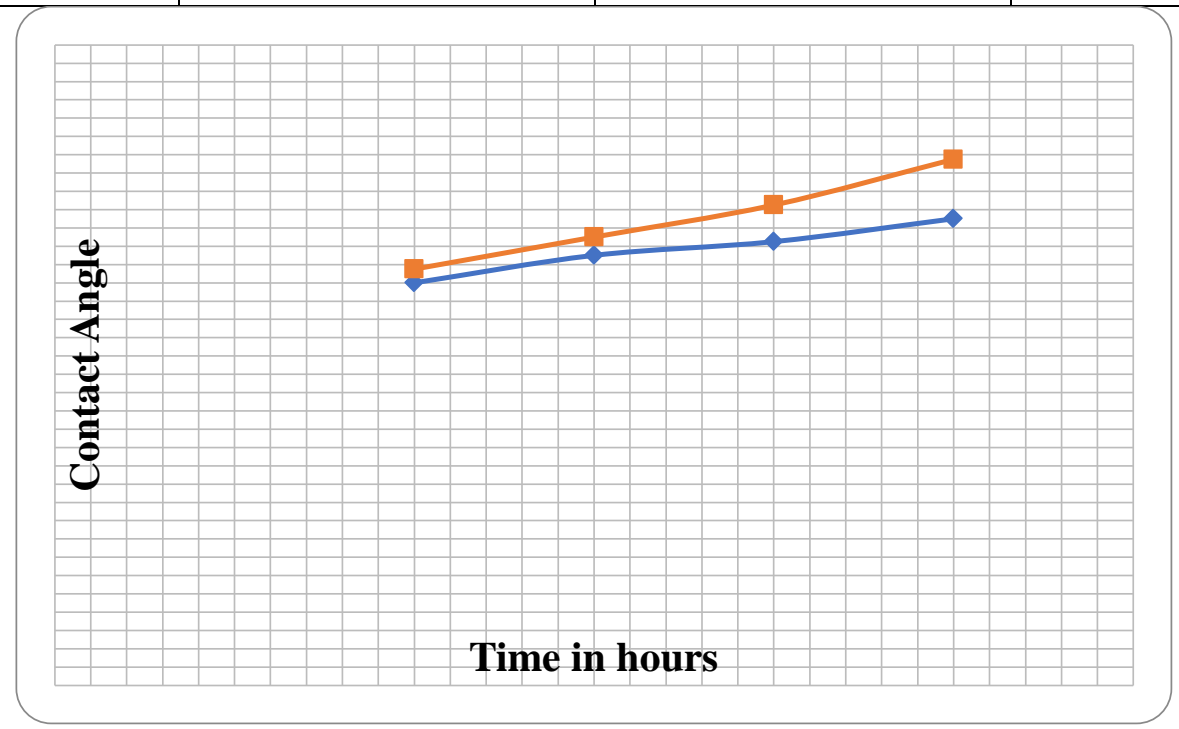

Figure 11: Field aged samples of RTV at $50^{\circ} \mathrm{C}$

\section{Conclusion}

we are finding out the contact angle, new have 115 at 10 Hours. The insulators are operating at $50^{\circ} \mathrm{C}$, which are shown in Table.5. Suspension insulators are saturated with pollutants within 5 to 6 months and the pollutant layer has been measured to be up to $8 \mathrm{~mm}$ thick.

\section{References}

[1] M. K. Chaudhury and M. J. Owen, "Hydrophobicity Loss and Recovery of Silicone HV Insulation", IEEE Trans. Dielectr. Electr. Insul., Vol. 6, No.5, pp. 695-702, 1999.

[2] A. Cherney, R. Hackam, K. G. Rutherford, "Chemical Changes at the Surface of RTV Silicone Rubber Coatings on Insulators During Dry-band Arcing", IEEE Trans. Dielectr. Electr. Insul., Vol. 1, No., pp. 106-123, 1994.

[3] J. Fitzgerald, M. J. Owen, S. D. Smith, M. Van Dyke, Synthesis and Properties of Silicones and Silicone-modified Materials, Published by American Chemical Society, Washington, DC, 2003.

[4] R. J. Hill, "Laboratory Analysis of Naturally Aged Silicone Rubber Polymer Insulators from Contaminated Environments, 138 to 765 kV," IEEE Transmission Distribution Conf., Texas, pp. 488-493, 1994.

[5] M. R. Guarniere, A. Posati, J-M George, S. Prat and G. de Simone, "First Experience with Factory Coated Glass Insulators on the Italian Transmission Network", presented at the Insulator News and Marketing Report (INMR) World Congress \& Exhibition on Insulators, Arresters \& Bushings, Rio de Janeiro, Brazil, 2007. 
[6] C.L. Mirley, J-A Ronzello and S. A. Boggs, "Field and Laboratory Aging of RTV Silicone Insulator Coatings", IEEE Trans. Power Delivery., Vol. 15, No. 4, pp 1298-1303, 2000.

[7] J.W. Chang and O. G. Amburgey, "Surface Hydrophobicity of Polymeric Materials used for Outdoor Insulation Applications”, IEEE Trans. Power Delivery, Vol. 5, No. 4, pp. 1921-1933, 1990.

[8] W.W. Guidi, J. Burnham, R. S. Gorur and J. Hall, "Accelerated aging and flashover tests on 138 kV non-ceramic line post insulators", IEEE Trans. Power Delivery, Vol. 8, pp. 325-336, 1993.

[9] IEC 62073, "Guidance on the measurement of wettability of insulator surfaces", edition 2003-06.

[10] K. Shenoi and R. S. Gorur, "Evaluating Station Post Insulator Performance from Electric Field Calculations", IEEE Trans. Dielectr. Electr. Insul., Vol. 15, No. 6, pp. 1731-1738, 2008.

[11] F. Hall, C. L. Nellis, S. S. Low and D. J. Lorden, "Rain and Contamination Tests of HVDC Wall Bushings with and without RTV Coating", IEEE Trans. Power Delivery, Vol. 6, No. 3, pp. 12891300, 1991.

[12] Xu, Wl Yin, A. Jeffery, J. Ponzello and S.A. Boggs, "Degradation of a silicone-based coating in a substation application," IEEE Trans. Power Delivery, Vol. 14, No.1, pp. 188- 193, 1999.

[13] H. Su, Z. Jia, Z. Guan and L. Li, "Durability of RTV-coated Insulators Used in Subtropical Areas”, IEEE Trans. Dielectr. Electr. Insul., Vol. 18, No. 3 , pp. 767-774, 2011. 